\title{
Bibliometric analysis of the literature on postural balance in children with Autism Spectrum Disorder
}

\author{
Erika Suenya Gomes Cordeiro ${ }^{1}$ \\ https://orcid.org/0000-0001-6167-0743 \\ Cíntia Alves Salgado Azoni ${ }^{1}$ \\ https://orcid.org/0000-0003-2175-9676 \\ Eliza Mikaele Tavares da Silva ${ }^{1}$ \\ https://orcid.org/0000-0002-9277-4657 \\ Fernando Henrique Fernandes ${ }^{1}$ \\ https://orcid.org/0000-0002-2801-977X \\ Carolina Daniel de Lima-Alvarez ${ }^{1}$ \\ https://orcid.org/0000-0002-2126-2937 \\ Juliana Maria Gazzola ${ }^{1}$ \\ https://orcid.org/0000-0002-9333-1831
}

Universidade Federal do Rio Grande do Norte, Natal, Rio Grande do Norte, Brasil.

Conflict of interests: Nonexistent

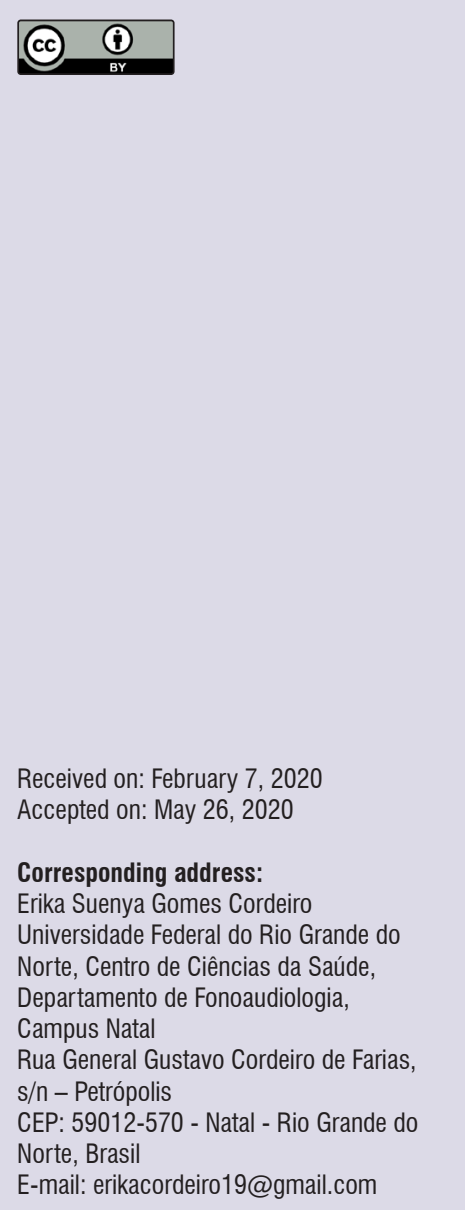

\section{ABSTRACT}

Purpose: to identify the state-of-the-art research on postural balance in children with autism spectrum disorder (ASD) in both Brazilian and international literature.

Methods: a bibliometric review, developed through bibliographical search in databases using the following descriptors: "postural balance" OR "vestibular diseases" OR "postural equilibrium" AND "autism". The eligibility criteria for sample selection were articles published in Brazilian and international journals, in either English or Portuguese. There was no restriction regarding the year of publication. The selection was based on reading the title, abstract, and lastly the full text of the articles potentially relevant for this review.

Results: 62 articles were found based on the eligibility criteria. The number of publications related to the study's theme peaked in 2015 and 2016, the first publication being from 1974. There was a predominance of studies published in the USA (37\%), in English, with a quantitative, cross-sectional approach. Most of the authors compared the performance in body balance tasks of children with ASD with that of children with typical development.

Conclusion: it was observed that body balance and postural control in children with ASD are growing trends in scientific publications.

Keywords: Autism; Postural Balance; Bibliometrics; Child; Review 


\section{INTRODUCTION}

Autism spectrum disorder (ASD) was first described by Kanner, in 1943, naming it "infantile autism". In 1944, Hans Asperger described the Asperger syndrome, whose signs are presently encompassed in the ASD. Autism is currently defined as a neurodevelopmental disorder that mainly causes deficits in social communication and the adoption of restricting and repetitive behavioral patterns, interests, or activities ${ }^{2}$.

Alterations in motor development and responses to sensory stimuli may be present in these children, although they are not included in the main characteristics of the $\mathrm{ASD}^{3}$. They can have hyper- or hypo reactivity (extreme responses, or little response) to the stimuli, as well as uncommon interest in some sensory stimuli present in the environment. Also, alterations in the processing, modulation, and sensory integration are common in children with autism spectrum disorder ${ }^{4,5}$.

Such alterations have direct implications on the development of the postural balance of the children with $\mathrm{ASD}^{6}$, reducing their postural stability. It should be kept in mind that maintaining postural balance is a complex process, resulting from the integration of the vestibular, proprioceptive, and visual systems.

The vestibular system picks up information on the head's angle acceleration in the sagittal, axial, and coronal planes, and on the linear body movements (back and forth, up and down). Through the vestibuloocular reflex (VOR), the vestibular system favors balance by generating ocular movements of equal speed and opposite direction to that of the head movements, thus stabilizing the image in the person's retina ${ }^{7}$. According to Furman et al. (2015) ${ }^{8}$, children with ASD have an increased ocular movement latency when compared with typical children. Vision, in its turn, favors the quick assimilation of the body movement and furnishes depth perception. The proprioceptive system, through muscle adjustments, informs the position and speed of the body in relation to the surface in a given moment. All the information picked up are sent to the central nervous system (CNS), where they are processed, modulated, and integrated ${ }^{7}$. Therefore, an alteration in any of these systems, or a failure in integrating them, will affect balance ${ }^{9}$.

Postural balance is an integral part of human motor control. It enables people to take and maintain the desired body position, either static or dynamic, in an activity ${ }^{10}$. This ability involves neural balance control and postural orientation ${ }^{11}$. Moreover, postural balance results from coordinated sensory and motor strategies to maintain posture, in order to stabilize the body's center of mass over its support base.

The postural balance system controls stability in a static posture, motion, and performing voluntary tasks. Postural orientation involves body alignment with gravity, support surface, visual environment, and other sensory points of reference. Postural control depends on the central neural interpretation of sensory information converging from vestibular and sensory visual systems ${ }^{12}$. Hence, postural control can be understood as the act of maintaining, reaching, or restoring a state of balance during any posture or activity. Balance is one of the characteristics of this ability.

In the literature, comparative studies between children in the autism spectrum and their peers with typical development showed differences between the performances in abilities of postural balance, motor coordination, and muscle tone. Regarding postural control, the children with ASD presented difficulties in maintaining balance in dynamic and static tests, $5^{6,9,13-16}$.

Based on assessments conducted in the everyday context of children with ASD, studies suggest that assessing their sensorimotor system is essential to plan their treatments, ${ }^{6,11}$. Unbalance in children presented with ASD may be an overlooked issue; however, alterations in balance affect these children's adequate development ${ }^{17}$. Thus, this bibliometric review aimed to identify the state-of-the-art scientific production on postural balance in children with ASD.

\section{METHODS}

This is a bibliometric review on the state-of-the-art research on postural balance and postural control in children with an autism spectrum disorder. In October and November 2018, national and international journals were searched for articles indexed in PubMed, LILACS, MEDLINE, Scopus, and SciELO databases. The search was updated in August 2019 to add more recent articles. Also, the references cited in the articles found in the initial search and Google Scholar were manually searched, so the largest number of articles would be identified. Based on the MeSH and DeCS (Health Sciences Descriptors) platforms, the following descriptors were used (in both English and Portuguese): "postural balance", "vestibular diseases", "postural equilibrium", and "autism", in these combinations: "postural balance" OR "vestibular diseases" OR "postural equilibrium" AND "autism". The search started by reading the title of the articles. The repeated articles were excluded, and the abstracts first and then 
the full texts were evaluated. The flowchart with the selection process is presented in Figure 1.

\section{Eligibility criteria}

Experimental, observational, and review articles published in Portuguese and English were included, with no restriction of the year of publication (a) whose participants were children diagnosed with ASD, with an evaluation of postural balance; (b) which used validated protocols to assess postural control and diagnose ASD. Opinion articles, case series, case studies, and communications were not included.

\section{Data extraction}

To characterize the articles, the following data were extracted and organized in tables: year of publication, name of the journal, country of publication, design of the research, keywords, purposes, and conclusion. For the analysis, the central tendency, such as mean, median, and frequency, was tested.

\section{LITERATURE REVIEW}

A total of 62 articles published between 1974 and July 2019 met the eligibility criteria. Of these, 43 were selected through PubMed, LILACS, MEDLINE, and Scopus. In SciELO, no articles corresponding to the selection criteria were found. The remaining articles were included through manual searches in Google Scholar and references cited in the articles. Articles not approaching the theme or population proposed, or that were duplicated in the databases, were excluded (Figure 1). No article was excluded based on its language - 61 articles were written in English, and one in Portuguese.

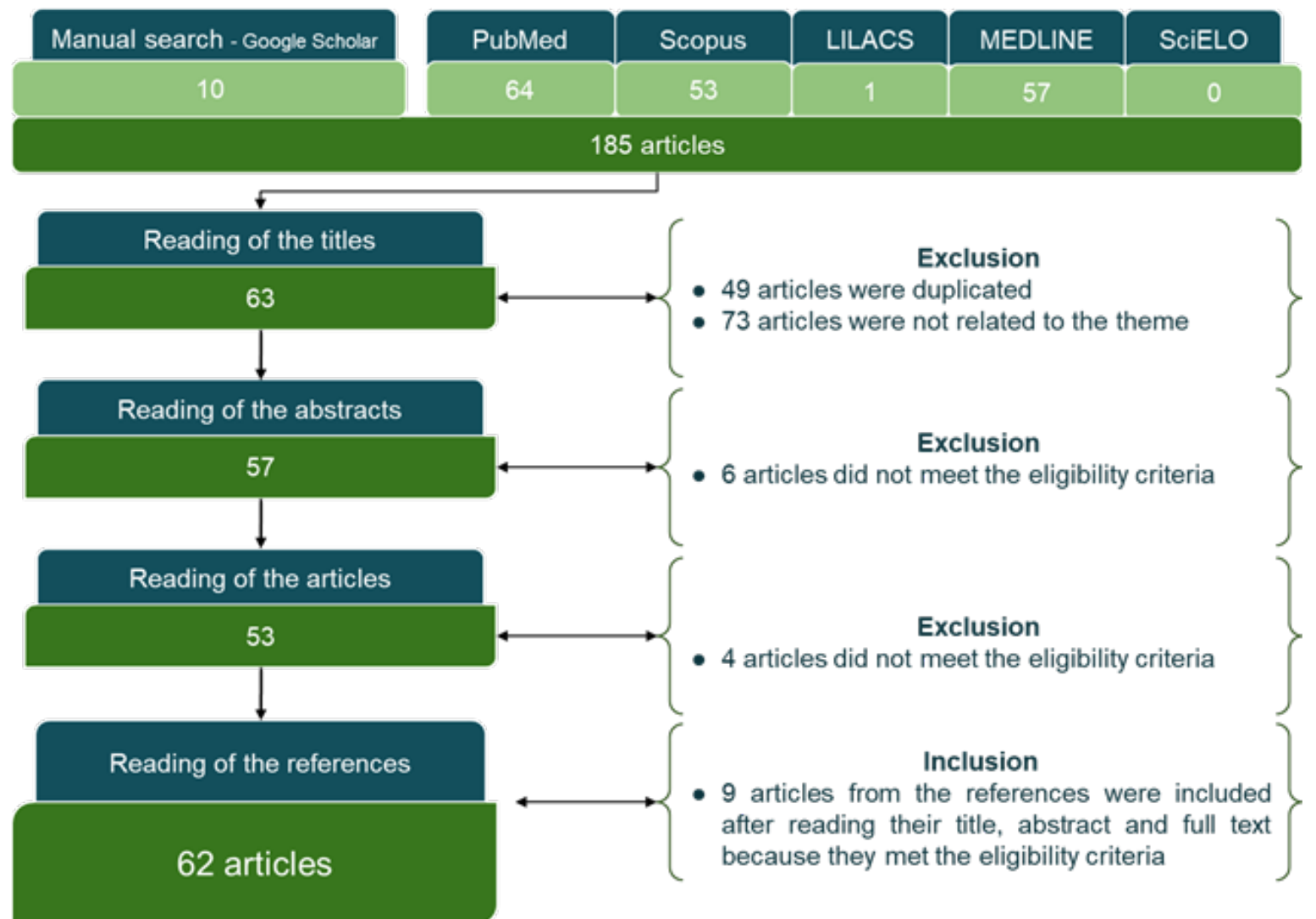

Figure 1. Flowchart of the search 
The first study approaching the proposed theme dates from 1974 - 30 years after autism was first described by Kanner ${ }^{2}$. It was written by Ornitz in the USA, and it assessed the effect of visual input on the nystagmus of children with autism. Throughout the years, studies on this theme were published more often. In 2018 and 2019, eight articles were found with different focuses, such as the effect of visual information on postural balance in children with ASD; the influence of proprioceptive and vestibular alterations on the postural balance in children with ASD; and the reflections of such difficulties on the activities of daily living. There has been a significant increase in the number of publications over the years, especially after 2012 (Figure 2). The graph shows the trend of publications for the upcoming years.

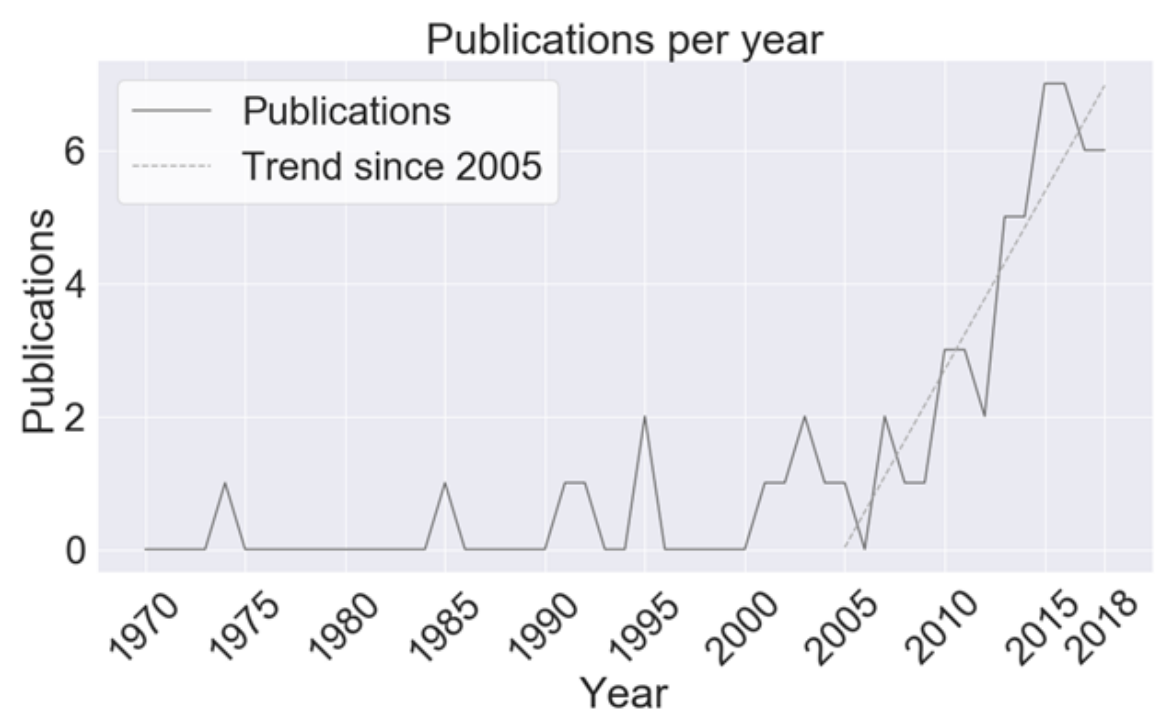

Figure 2. Publications per year

Characteristics related to motor development and postural balance, although they are not considered primary criteria for the diagnosis of ASD, are themes increasingly approached, with a larger number of publications in the last 45 years.

The largest number of publications took place in 2015 and 2016, with seven articles each. In 2017 and 2018, there were also publications in France and Australia, revealing different countries increasingly involved in research on postural control of children with ASD. In France, there is a research team whose studies are mostly on this theme. Its main author is Maria Pia Bucci, who published articles in 2013, 2017, and 2018.

The USA accounts for $37 \%$ of the studies conducted in this period; $16.1 \%$ of them were carried out in France; Australia and Iran contributed with $8 \%$ of the studies each; the Netherlands contributed with almost $5 \%$. The production of the remaining 11 countries corresponded to $25.8 \%$ of the total sample (Figure 3). In Latin America, only one article was found, published in Brazil. The publications are predominantly in English, whose only exception is the Brazilian article, in Portuguese. 


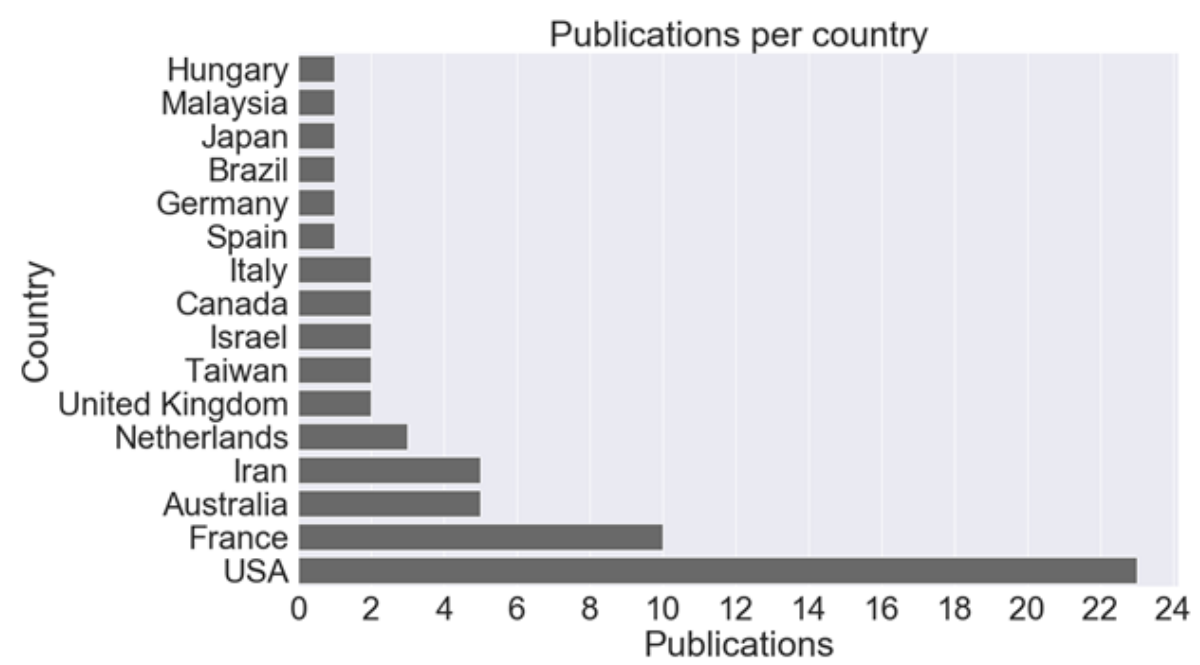

Figure 3. Number of publications per country

The researchers who published most articles as first authors between 1974 and 2017 are shown in Figure 4, with three articles each.
Postural control has been investigated mainly by neuroscientists - there was only one occupational therapist among the authors who most published on the theme.

\begin{tabular}{|c|c|c|c|}
\hline Author's name & Bachelor's degree & Postdoctoral degree & Place of the research \\
\hline Maria Pia Bucci & Biology & Neurosciences & France \\
\hline Kimberly Fournier & Bachelor of Science & Biomechanics & USA \\
\hline Yi Huey Lim & Occupational Therapy & Occupational Therapy & Australia \\
\hline Amir-Hossein Memari & Psychology & Neurosciences & Iran \\
\hline
\end{tabular}

Figure 4. Characterization of the main authors

The 31 journals that published articles on the theme are focused on neurosciences, physical therapy, occupational therapy, psychology, and autism. Two of them stood out: Autism and Developmental Disorders
(29\%), and Gait \& Posture (9.7\%). As for the other ones, they were homogeneous in the number of publications, with one or two on average. 


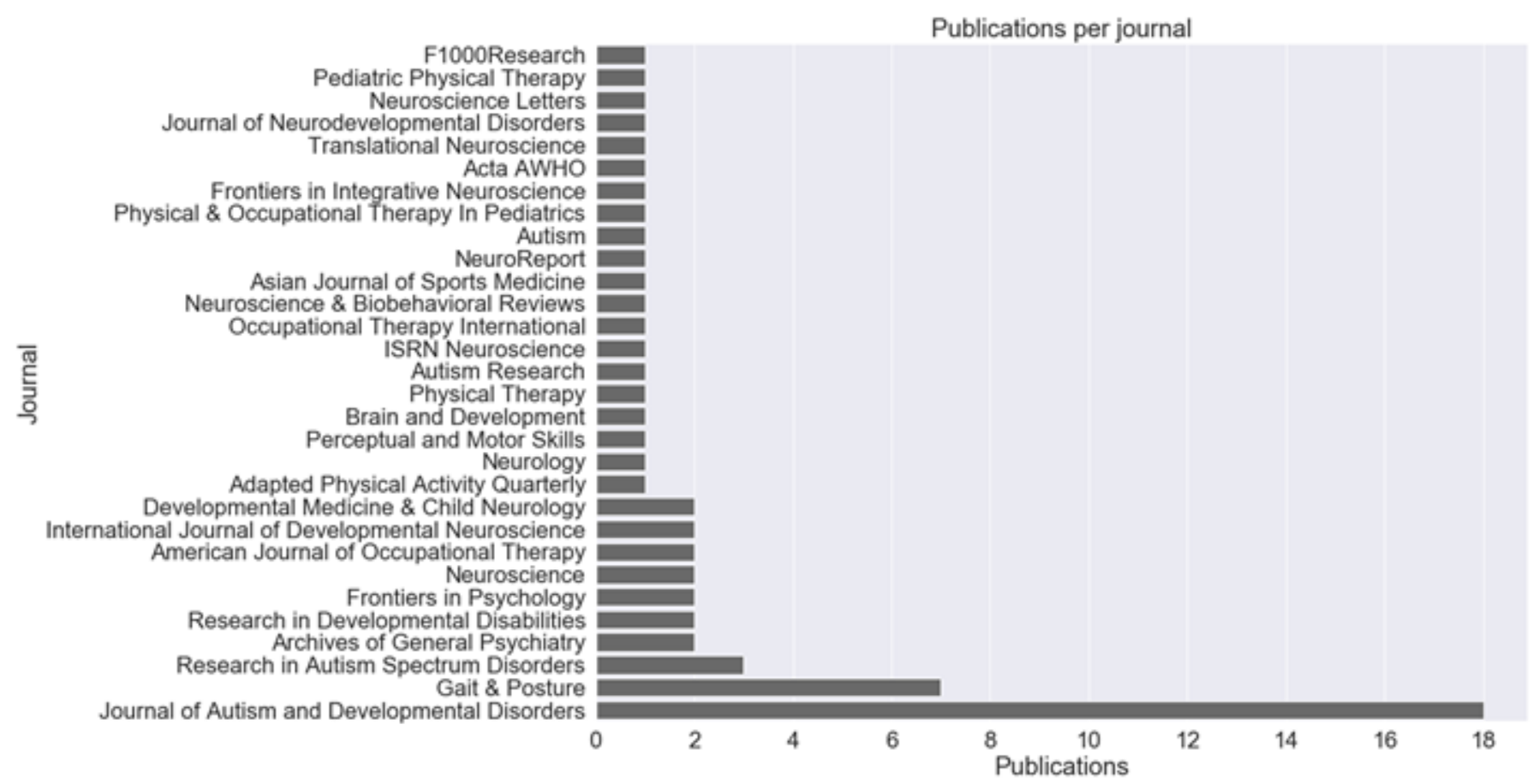

Figure 5. Number of publications per journal

The 10 most recurrent keywords in the publications are given in Figure 6. "Autism" was the most frequent keyword, followed by its correspondent ones, "autism spectrum disorder" and "autism spectrum disorders". Regarding postural balance, the most repeated term was "postural control", even though it is not on the MeSH platform, which employs different words to characterize postural control. These words were collected from the keywords listed in the selected articles. The keywords for this study were chosen based on the MeSH and DeCS platforms, which explains why the descriptors are different from those found in the review.

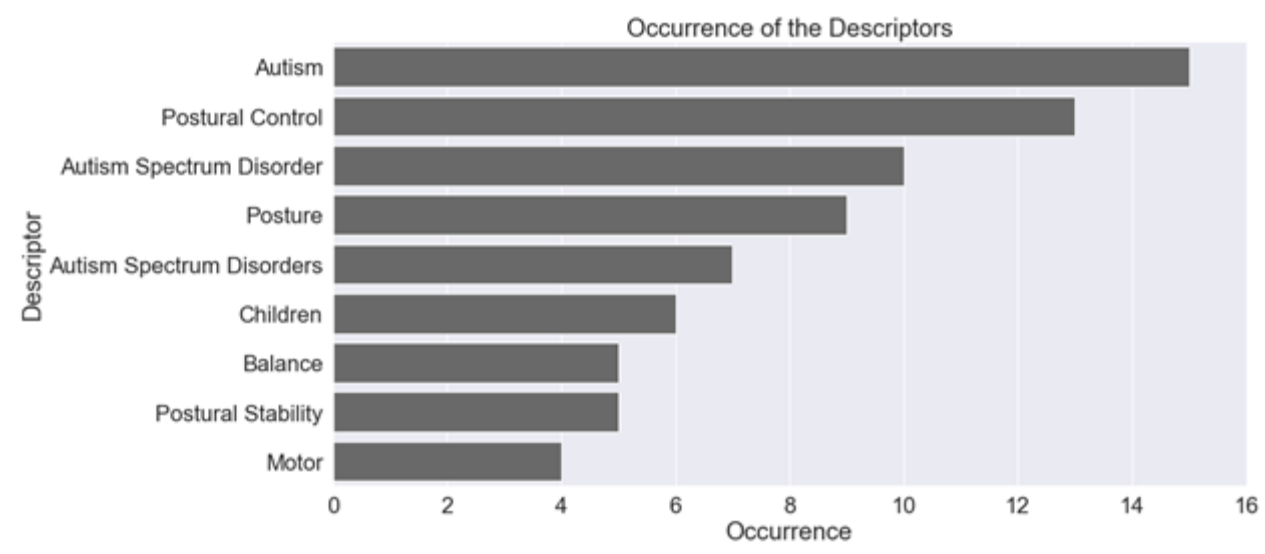

Figure 6. Keywords of the selected articles 
Most of the studies included here had a quantitative approach. Only $6.5 \%$ were qualitative; these were literature reviews or systematic reviews. Observational articles predominated (84\%), usually comparing children with autism with neurotypical ones. Some articles also investigated the failure in the relationship

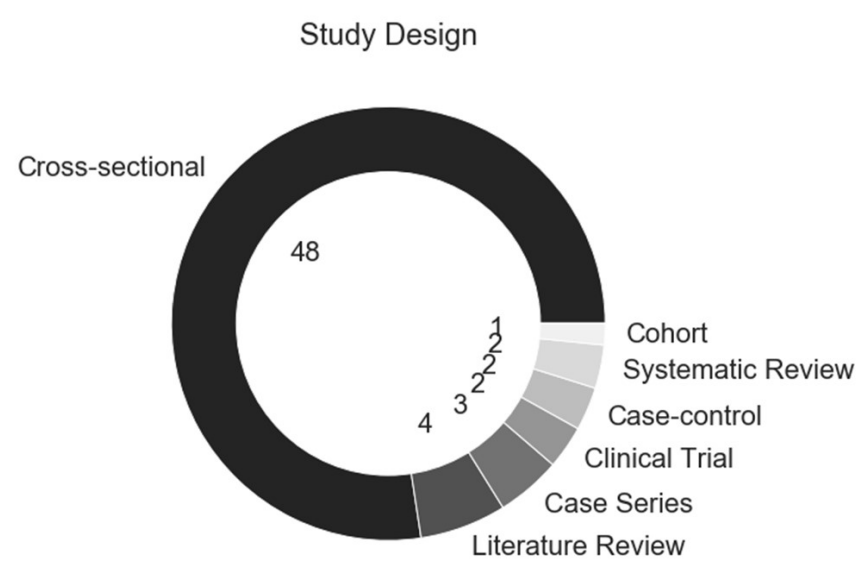

Type of Approach

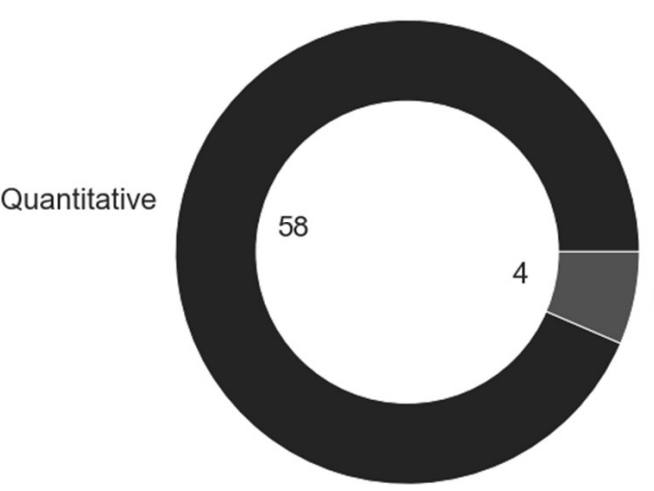

Qualitative

Figure 7. Methodological aspects of the studies

The purpose and conclusion of the articles comprising this bibliometric review are described in Figure 8. Moreover, as seen in Figure 9, 66\% of the publications aimed to compare the performance in the body balance of children with ASD in relation to children between postural control and other demands in ASD. Eight percent of the articles were experimental studies, two of which were clinical trials (Figure 7). The mean number of participants with ASD per study ranged from 15 to 30 . Nevertheless, there were articles with as little as one and as much as 170 individuals.

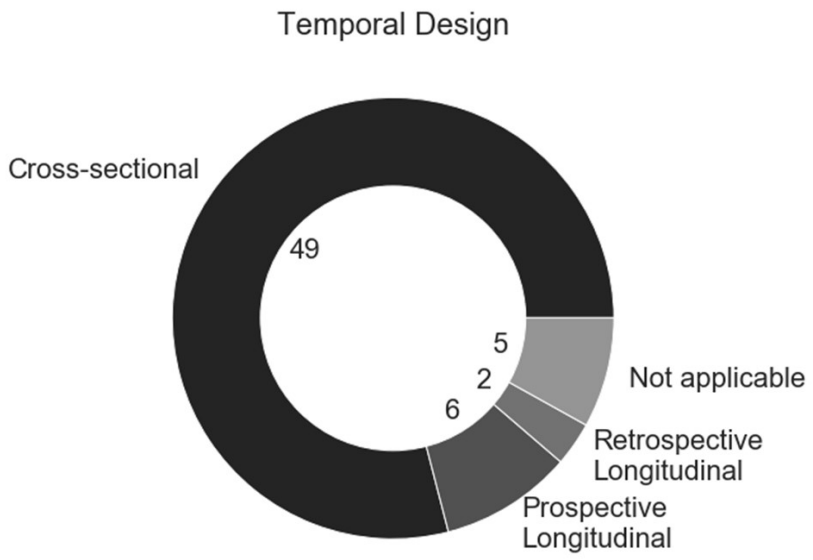

Type of Study

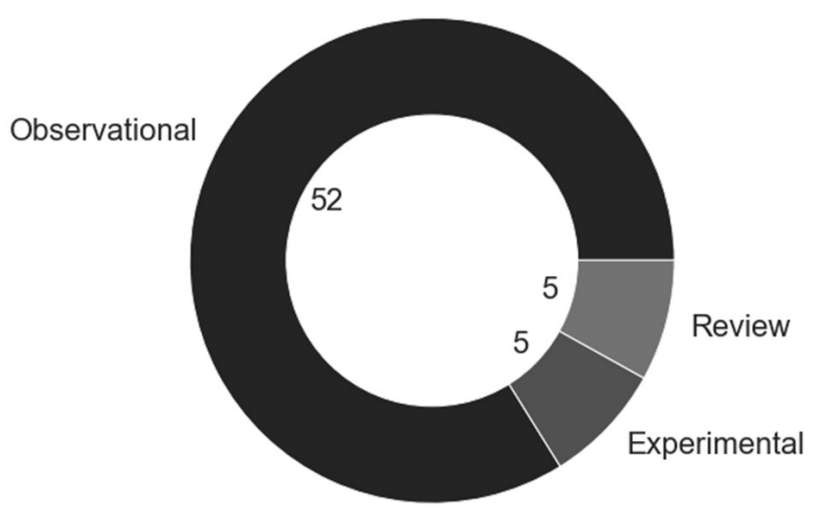

with typical development. The remaining studies dealt with literature reviews, evaluation methods, interventions in body balance, and verification of other motor characteristics in children with ASD. 


\begin{tabular}{|l|l|}
\hline \multicolumn{2}{|l|}{ Purpose of the selected articles } \\
\hline 1 & To compare the children with ASD with the control group regarding the performance of body balance \\
\hline 2 & To assess the performance of body balance in children with ASD \\
\hline 3 & To verify the effectiveness of a body balance assessment method \\
\hline 4 & An intervention for body balance \\
\hline 5 & Other assessments related to motor development \\
\hline Conclusion of the selected articles \\
\hline 1 & The children with ASD had alterations in body balance when compared with the control group \\
\hline 2 & There was no significant difference between the groups \\
\hline 3 & The children with ASD had difficulty performing the tasks \\
\hline 4 & The children had no difficulties in the tasks \\
\hline 5 & The instrument was effective to assess body balance \\
\hline 6 & The instrument was not effective to assess body balance \\
\hline 7 & There were benefits to the children's performance \\
\hline 8 & There were no benefits to the children's performance \\
\hline
\end{tabular}

Figure 8. Classification of purpose and conclusion of the selected articles

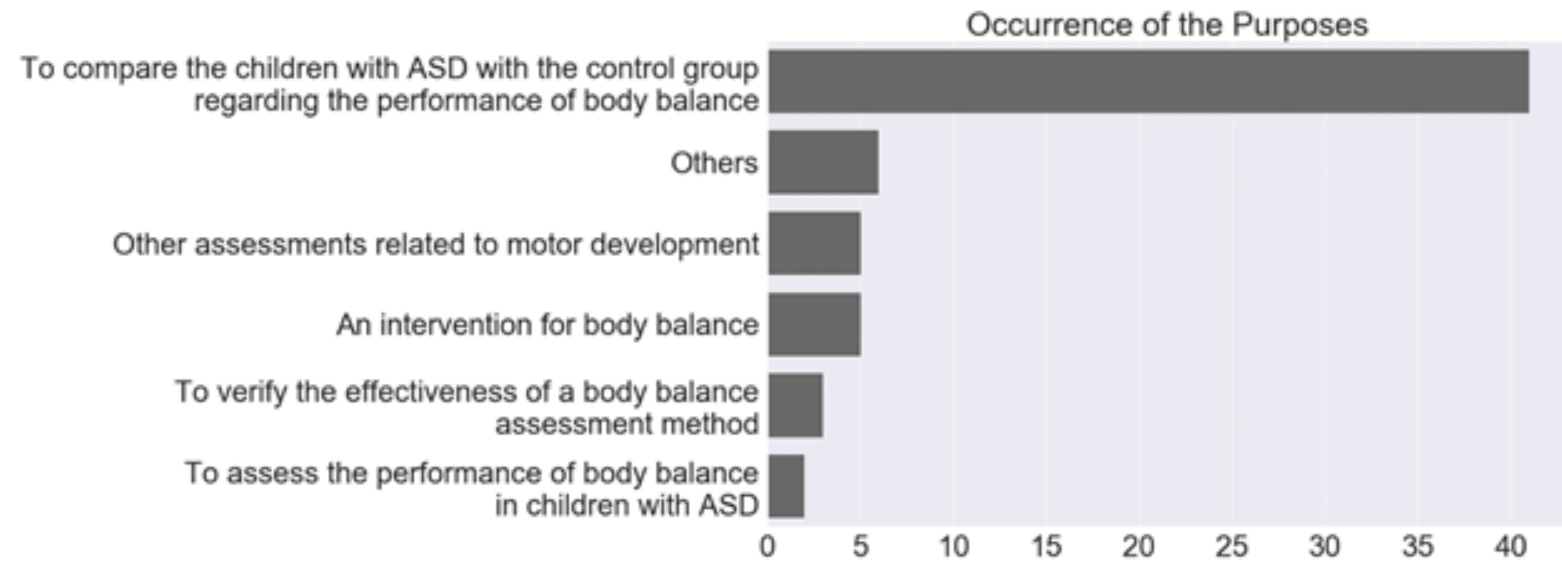

Figure 9. Purpose of the selected articles

Most of the studies showed that the children with ASD had difficulties in performing body balance tasks when compared with the control group, as seen in Figure 10. The other conclusions described benefits from the interventions related to difficulties in balance, as well as new assessment methods that proved to be effective.

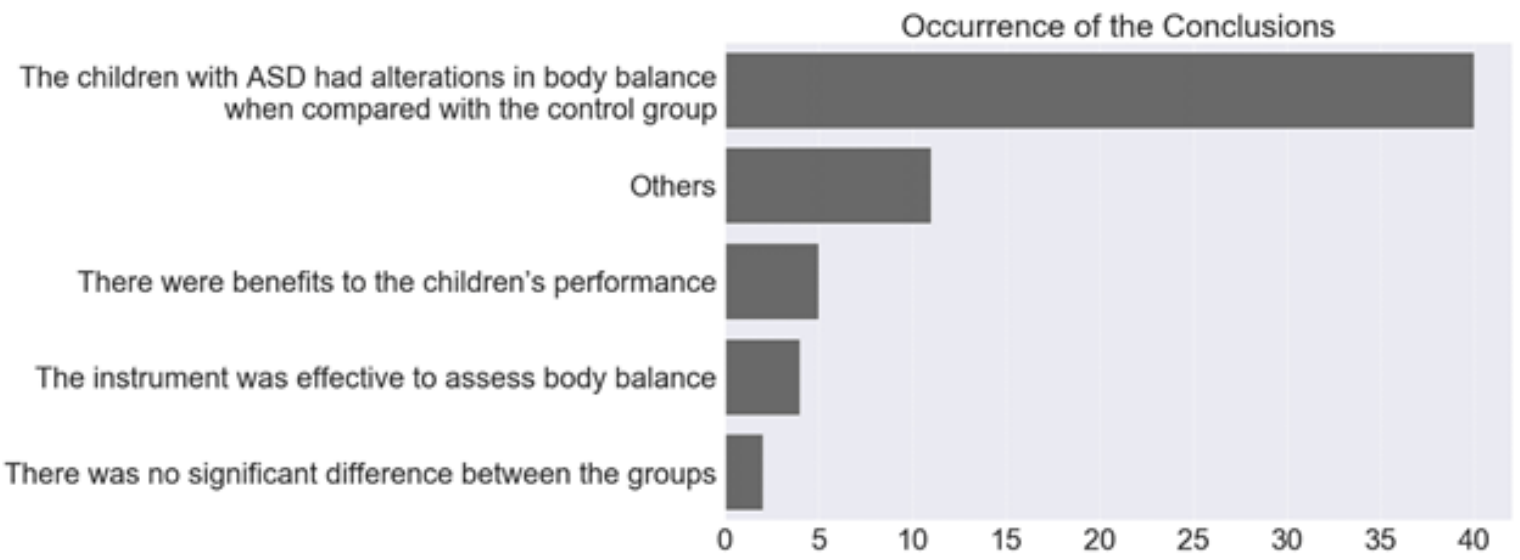

Figure 10. Conclusion of the selected articles 
According to the DSM- $5^{2}$, motor alterations are not described as part of the diagnostic criteria for ASD. Nonetheless, it was observed in the selected articles that children with ASD have worse performance in body balance tasks when compared with children with typical development.

\section{CONCLUSION}

This bibliometric review aimed to identify the stateof-the-art scientific production on postural balance of children with ASD. A total of 62 articles published between 1974 and 2019 were found. The years of publication indicate that the number of papers approaching the relationship between body balance and autism spectrum disorder has been growing since 2005. Studies published in the USA predominated, as well as those with observational and cross-sectional design.

Researchers from France and the USA were the ones who produced most articles. The majority of the studies found compared children with ASD with children with typical development regarding their performance in body balance tasks. This article suggests that more studies analyzing the characterization and the effects of intervention in body balance in the everyday life of children with ASD be produced.

\section{REFERENCES}

1. Kanner L. Autistic disturbances of affective contact. Nerv Child. 1943;2:217-50.

2. American Psychiatric Association. Diagnostic and Statistical Manual of Mental Disorders: DSM-5. 5a ed. Artmed; 2013.

3. O'Neill M, Jones RSP. Sensory-perceptual abnormalities in autism: a case for more research? J Autism Dev Disord.1997;27(3):283-94.

4. Kern JK, Trivedi MH, Garver CR, Grannemann BD, Andrews AA, Savla JS et al. The pattern of sensory processing abnormalities in autism. Autism. 2006;10(5):480-94.

5. Crane L, Goddard L, Pring L. Sensory processing in adults with autism spectrum disorders. Autism. 2009;13(3):215-28.

6. Wang Z, Hallac RR, Conroy KC, White SP, Kane $\mathrm{AA}$, Collinsworth AL et al. Postural orientation and equilibrium processes associated with increased postural sway in autism spectrum disorder (ASD). J Autism Dev Disord. 2016;8(1):1-17.

7. Hain TC, Ramaswamy TS, Hillman MA. Anatomia e fisiologia do sistema vestibular normal. In: Herdman
SJ. Reabilitação vestibular. $2^{\mathrm{a}}$ ed. Barueri: Manole; 2002.

8. Furman JM, Osorio MJ, Minshew NJ. Visual and Vestibular Induced Eye Movements in verbal children and adults with Autism. Autism Res. 2015;8(6):658-67.

9. Molloy CA, Dietrich KN, Bhattacharya A. Postural stability in children with Autism Spectrum Disorder. J Autism Dev Disord. 2003;33(6):643-52.

10. Cupps B. Postural Control: a current view. NDTA Network. 1997;14:3-8.

11. Horak FB, Macpherson JM. Postural orientation and equilibrium. In: Rowell LB, Shepherd JT (eds). Handbook of physiology: Section 12: Exercise: regulation and integration of multiple systems. Nova York (Nova York), Oxford University Press, 1996. p.255-92.

12. Horak FB. Postural control. In: Binder MD, Hirokawa $\mathrm{N}$, Windhorst U. Encyclopedia of Neuroscience. Berlin (Heidelberg), Springer, 2009. p.3212-3.

13. Gouleme N, Scheid I, Peyre H, Seassau M, Maruani $\mathrm{A}$, Clarke $\mathrm{J}$ et al. Postural control and emotion in children with autism spectrum disorders. Transl Neurosci. 2017;8(1):158-66.

14. Kohen-Raz R, Volkman FR, Cohen DJ. Postural control in children with autism. J Autism Dev Disord. 1992;22(3):419-32.

15. Greffou S, Bertone A, Hahler EM, Hanssens JM, Mottron L, Fauber J. Postural hypo-reactivity in autism is contingent on development and visual environment: a fully immersive virtual reality study. J Autism Dev Disord. 2012;42(6):961-70.

16. Minshew NJ, Sung KB, Jones BL, Furman JM. Underdevelopment of the postural control system in autism. Neurology. 2004;63(11):2056-61.

17. Medeiros IR, Bittar RSM, Pedalini MEB, Lorenzi MC, Formigoni LG, Bento RF. Vestibular rehabilitation therapy in children. Otol Neurotol. 2005;26(4):699-703. 